and life events in working class women. Archives of General Psychiatry 43:315323, 1986

65. Akiskal HS, Hirschfeld RMA, Yerevanian BI: The relationship of personality to affective disorders: a critical review. Archives of General Psychiatry 40:801-810, 1983

66. Gershon ES, Dunner DL, Sturt L, et al: Assortative mating in the affective disorders. Biological Psychiatry 7:6374, 1973

67. Dunner DL, Fleiss JL, Addonizio G, et al: Assortative mating in primary affective disorders. Biological Psychiatry 11:43-51, 1976

68. Rutter M, Quinton D: Psychiatric disorder: ecological factors and concepts of causation, in Ecological Factors in Human Development. Edited by McGuirk H. Amsterdam, Elsevier, 1977

69. Birtchnell J, Kennard J: Marriage and mental illness. British Journal of Psychiatry 142:193-198, 1983

70. Davenport YB, Adland ML, Gold PW, et al: Manic-depressive illness: psychody- namic features of multigenerational families. American Journal of Orthopsychiatry 49:34-35, 1979

71. Mayo JA: Marital therapy with manicdepressive patients treated with lithium. Comprehensive Psychiatry 20:419 426, 1979

72. Hoover CF, Fitzgerald RG: Marital conflict of manic-depressive patients. Archives of General Psychiatry 38:6567,1981

73. Koenigsberg HW, Handley R: Expressed emotion: from predictive index to clinical construct. American Journal of Psychiatry 143:1361-1373, 1986

74. Kanter J, Lamb HR, Loeper C: Expressed emotion in families: a critical review. Hospital and Community Psychiatry 38:374-380, 1987

75. Vaughn CE, Leff JP: The influence of family and social factors on the course of psychiatric illness: a comparison of schizophrenic and depressed neurotic patients. British Journal of Psychiatry 129:125-137, 1976

76. Hooley JL, Orley J, Teasdale JT: Levels of expressed emotion and relapse in depressed patients. British Journal of Psychiatry 148:642-647, 1986

77. Miklowitz DJ, Goldstein MJ, Nuechterlein $\mathrm{KH}$, et al: Expressed emotion, affective style, lithium compliance, and relapse in recent-onset mania. Psychopharmacology Bulletin 22:628632, 1986

78. Fadden G, Bebbington P, Kuipers L: The burden of care: the impact of functional psychiatric illness on the patient's family. British Journal of Psychiatry 150:285-292, 1987

79. McHugh PR, Slavney PR: The Perspectives of Psychiatry. Baltimore, Johns Hopkins University Press, 1983

80. Schwartz MA, Wiggins OP: Systems and the structuring of meaning: contributions to a biopsychosocial medicine. American Journal of Psychiatry 143:1213-1221, 1986

81. Kandel ER: Psychotherapy and the single synapse: the impact of psychiatric thought on neurobiologic research. New England Journal of Medicine 301:1028-1037, 1979

\title{
A Comparison of Clinical and Judicial Procedures for Reviewing Requests for Involuntary Medication in New York
}

Francine Cournos, M.D. Karen McKinnon, M.A. Carole Adams, B.A.

The Rivers v. Katz decision substituted judicial review for ad ministrative review of requests for involuntary medication of patients in New York State mental hospitals. Thischange, prompted byconcern for the rights of involuntarily committed patients, did not delay ordiminish the use of involuntary medication in a large state bospital. Advantages of judicial review include a better understanding by clinicians of the legal basis for involuntary medication and greater patient participation in the review procedure. Disadvantages include lack of an independent clinical review and increased costs.

Hospital and Community Psychiatry
Two prominent issues at the interface of psychiatry and the law are the patient's right to refuse treatment and the procedures hospitals use to obtain authorization for involuntary medication (1-4). To decide these issues, New York State had relied on a clinical administrative review process (5) until June 10,1986 , when, in a decision known as Rivers $v$. Katz (6), the New York State Court of Appeals unanimously overturned this procedure. The court ruled that a judicial hearing would be required to determine if a patient in a state mental hospital should be forcibly medicated with antipsychotic drugs. This ruling was interpreted to apply to other types of psychiatric inpatient settings and treatments.

There have been many papers discussing the right to refuse treat- ment. As Appelbaum and Hoge (7) point out, however, in their extensive review of published and unpublished papers on the topic, systematic studies have been rare. Most studies have looked at the characteristics of patients who refuse treatment (7-11). The impact of different systems of review has not been explored in depth, although, regardless of the procedure, treatment refusals appear to be overridden 67 percent to 100 percent of the time $(7,12,13)$. This study examined the impact of the Rivers decision at a large state hospital.

Before the Rivers decision Before Rivers, the treating physician initiated the application for involuntary treatment. The patient was entitled to an appeal at each 
of three ascending levels of authority: the head of the service, the facility director, and the regional director within the state Office of Mental Health (5). In practice, if any of these officials were not physicians, the review was done by a designated physician. The regulations did not specify the nature of the review. The treating psychiatrist usually submitted a psychiatric summary that included the patient's psychiatric history, the reasons for the current hospitalization, the results of a mental status examination, the patient's diagnosis, and a brief statement about the treatment being requested, in addition to the justification for requesting involuntary treatment. The head of the service and the facility director or their designees wrote brief corroborating statements. At the regional office an independent psychiatrist reviewed the material, raised questions if necessary, and prepared a simple statement approving or denying the request.

Additionally, New York State provides free legal representation to patients through the Mental Health Legal Service (MHLS). The head of the service was obligated to notify MHLS when an application for involuntary medication was made.

\section{Rivers v. Katz}

The court in Rivers $v$. Katz determined that New York State's administrative review procedure did

Dr. Cournos is assistant clinical professor of psychiatry at the Columbia University College of Physicians and Surgeons and director of the Washington Heights community service of the New York State Psychiatric Institute, 722 West 168th Street, New York, New York 10032. Ms. McKinnon is program evaluation specialist at the New York State Psychiatric Institute. Ms. Adams is legal affairs coordinator at Manhattan Psychiatric Center at Ward's Island in New York City. not sufficiently protect the due process rights of involuntarily committed patients. Specific inadequacies of the procedure included the lack of standards for choosing medication and for determining the duration of involuntary treatment.

The court noted the longrecognized distinction (14) between police power, the state's right to respond immediately to imminent danger, and parens patriae power, the state's obligation to care for persons who are incapable of caring for themselves. The court required that whenever the forcible administration of antipsychotic drugs was based on the exercise of parens patriae power, the decision would be made by judicial review.

The court emphasized that the forcible administration of antipsychotic drugs could occur only if the patient lacked the capacity to make a reasoned decision about the proposed treatment. If the patient lacked such capacity, the court was then directed to determine "whether the proposed treatment is narrowly tailored to give substantive effect to the patient's liberty interest, taking into consideration all relevant circumstances, including the patient's best interests, the benefits to be gained from the treatment, the adverse side effects associated with the treatment, and any less intrusive alternative treatments" (6).

\section{After the Rivers decision}

After Rivers, a modified clinical administrative procedure continued to be required before the court hearing (15). New regulations reduced the number of necessary clinical evaluators from four to two-the treating physician and the clinical director or designee. The Mental Health Legal Service remained available to represent the patient.

The new procedure required each of the two evaluating psychiatrists to interview the patient personally. At state hospitals, psychiatrists were required by policy to complete an eight-page form that included a psychiatric summary, a proposed course of treatment, a formal evaluation of the patient's capacity, and documentation that the patient had received an explanation of the proposed treatment. The hospital then had to file four separate legal documents with the court, and the case was brought to a hearing.

\section{Method}

This study examined the impact of the Rivers decision on one state hospital, Manhattan Psychiatric Center. The center has approximately 1,200 beds and is one of five large adult state hospitals in New York City. Among these hospitals, Manhattan Psychiatric Center accounted for 42 percent of the involuntary treatment decisions in 1985.

We sought to discover if the more intricate procedure initiated after the Rivers decision discouraged clinicians from applying to medicate patients involuntarily or delayed treatment. Additionally we examined whether the types of patients selected for involuntary treatment changed after the new procedure was implemented and if judges were more likely than clinicians to uphold the patient's refusal.

Data were collected by reviewing all documents generated by the involuntary treatment procedures, including clinical evaluations, patients' statements, legal opinions, notes of court hearings, and final outcome reports. These documents were supplemented with information from the state Office of Mental Health's computerized patient information system and from patients' charts. The study compared data collected for a 12-month period from January 1 to December 31, 1985, with data collected for the 12-month period following implementation of the new procedure, August 8, 1986, to August 7, 1987.

Two of the authors were directly involved with the review process. One (FC) had been designated by the regional director to 
make the final decisions for all cases processed in 1985. The other author (CA) was the coordinator of patient legal affairs for Manhattan Psychiatric Center, and, after Rivers, she was responsible for reviewing the adequacy of all legal documents and filing them with the court, scheduling hearings, and notifying the physician, patient, and MHLS of the court date. In addition, she also attended every hearing. The third author (KM), who had no direct involvement in the review process, was responsible for gathering and scoring the data.

\section{Results}

\section{Cases approved}

There was no significant difference in the number of cases processed or approved before and after the Rivers decision. A total of 42 cases were decided during the two periods. Of the 21 cases completed in 1985, 20 were approved and one was denied. In the 198687 post-Rivers period, 21 cases were decided, of which 18 were approved and three denied. The denial in the pre-Rivers period and one of the three denials in the post-Rivers period were based on insufficient clinical justification. Procedural errors in the applications prevented the judge from deciding the other two cases denied in the post-Rivers period. One of these cases was returned to court following the study, and medication was approved. These results demonstrate that the new procedure did not have a significant effect on the frequency of requests for and approval of involuntary treatment.

There were no significant demographic differences between the pre-Rivers and post-Rivers groups of patients. Patients were similar in age, sex, ethnicity, educational background, diagnosis, and history of hospitalization.

The average age was 55 for the women and 38 for the men. Of the 42 patients whose cases were processed, 36 percent were female, and 64 percent were male. The age and sex distributions were consistent with the composition of the total hospital population.

Fifty-seven percent of the patients were black, 26 percent were white, 12 percent were Hispanic, and 5 percent were Asian. Fiftyfive percent had at least a high school diploma.

Sixty-four percent of the patients had a diagnosis of schizophrenia; 10 percent had schizoaffective disorder; 7 percent had an affective disorder; 7 percent had organic brain syndrome; and 7 percent had atypical psychosis. Five percent had other diagnoses.

The average number of hospitalizations before the current episode was 5.3. Patients in the pre-Rivers group had been in the hospital for an average of 22 months at the time the involuntary treatment request was initiated. In the post-Rivers group, patients had been hospitalized an average of 11 months when involuntary treatment was recommended. This trend fell short of statistical significance and may have been related to the transfer of 100 long-stay patients to other facilities between the two study periods.

Both the clinical and the judicial procedures were time-consuming, but there was no significant difference between the study periods in the average time elapsed from the first evaluation until the final decision. The process took an average of 5.4 weeks under the old procedure and 5.8 weeks under the new procedure.

\section{Reasons for involuntary medication}

Clinicians' reasons for recommending involuntary medication fell into five categories: risk of assault, risk of suicide, serious untreated medical illness, severe mental illness with regression, and severe mental illness without regression. Regression refers to behaviors that interfere with self-care and includes refusal to eat, bathe, dress, or engage in minimal social interaction. Mental illness without regression was the only category that did not include behavior posing a danger to either the patient or others.
The primary reason for treatment refers to the issue that received the strongest emphasis in the application. For the pre-Rivers sample, the primary reasons for requesting involuntary medication were severe mental illness with regression for nine of 21 subjects (43 percent), risk of assault for five patients ( 24 percent), serious untreated medical illness for four patients (19 percent), risk of suicide for two patients (10 percent), and mental illness without regression for one patient ( 5 percent).

For most pre-Rivers patients, there was more than one reason for the treatment request, and 43 percent of the sample were considered to be simultaneously regressed, suicidal or assaultive, and medically ill. In addition to refusing psychotropic medication, these patients often refused other interventions. Eighty-one percent of the sample had episodes of refusing physical care, including refusal of food (29 percent), refusal to bathe (38 percent), and refusal of medical evaluation or care ( 57 percent).

After Rivers, the primary reasons for requesting treatment were severe mental illness with regression for seven of the 21 patients (33 percent), risk of assault for six patients (29 percent), severe mental illness without regression for six patients (29 percent), and serious untreated medical illness for two patients (10 percent). Risk of suicide was not given as a primary reason for requesting treatment for any of the 21 post-Rivers subjects. However, 10 percent of the sample were considered simultaneously regressed, suicidal or assaultive, and medically ill, and 71 percent had episodes of refusing physical care.

The only significant difference between the pre- and post-Rivers samples in the primary reason for requesting medication was the number of patients for whom the justification was mental illness without regression. Before Rivers, there was only one such case, and this request was denied. Of the six such cases after Rivers, five were ap- 
proved and one denied. This difference was statistically significant $\left(\mathrm{x}^{2}=4.3, \mathrm{df}=1, \mathrm{p}<.05\right)$.

Although the number of cases in each sample is small, the results suggest that clinicians were more willing after Rivers to request involuntary treatment on the basis of serious mental illness, even if the patients presented no risk of harm to themselves or others. This trend seemed to be consistent with the court's focus on capacity, rather than dangerousness, in determining the appropriateness of involuntary treatment based on the parens patriae rationale.

\section{Participants' roles}

Before Rivers, patients took little part in the review procedure. The Mental Health Legal Service, although available to patients, wrote a statement in only one of the 21 pre-Rivers cases. No patient submitted a personal statement. The final decision was issued from a distant administrative office.

The new procedure allows much more interaction. The hearing takes place on the premises of the hospital and generally lasts 30 to 45 minutes. At least five people are present: the judge, the Mental Health Legal Service lawyer representing the patient, the treating psychiatrist, the hospital's legal affairs coordinator, and a lawyer from the state attorney general's office representing the hospital.

In two of the cases in the post-Rivers sample, an independent psychiatrist was also present. In addition, patients are permitted to attend the hearings, affording them the opportunity to hear their situations presented from the perspective of the hospital staff. Fifteen patients in the post-Rivers sample came to court. Eight of these patients testified, and five were able to make statements relevant to the treatment decision. In the only case in which the request for treatment was denied by a judge on clinical grounds, the patient had come to court and had been able to provide coherent and relevant testimony about his wish not to be medicated.

No MHLS lawyer argued that patients had the capacity to make the treatment decision. Rather, MHLS arguments in the postRivers cases focused on whether the treatment was in the best interests of the patient. Side effects

Fifteen patients in the post-Rivers sample came to court. Eight of these patients testified, and five were able to make statements relevant to the treatment decision.

were mentioned as a reason to uphold the refusal in 19 of 21 cases and were the sole reason in 11 cases. Less frequently mentioned were unresolved clinical questions, legal obstacles other than capacity, and possible alternative treatments.

Nine different judges decided the 21 post-Rivers cases. They played a fairly active role, asking questions about the diagnosis in 29 percent of the cases and questioning the proposed treatment in 67 percent of the cases. Nonetheless, in all but one case in which the request for treatment was approved, the judge accepted the plan for medication exactly as outlined by the physician. In that instance, the patient strongly objected to the physician's first choice of drug, haloperidol, because of previously experienced side effects. The judge ordered the use of the physician's second choice of medication, chlorpromazine.

\section{Duration of treatment}

The pre-Rivers regulations did not include limits on the length of time for which medication could be approved. In practice, however, the New York City regional office routinely approved treatment for a three-month period. Treating staff could submit follow-up reports and request treatment extensions for three-month blocks of time. In the pre-Rivers sample, an extension of the initial treatment approval period was requested for 50 percent of the patients. The average period of approval for involuntary treatment was 6.8 months.

Under the new procedure, judges approved involuntary treatment for periods of time ranging from 30 days to six months, with an average of 3.7 months. However, there is no court procedure for requesting an extension of ongoing involuntary treatment. An entirely new application is required to extend treatment, and the hearing is scheduled with the next available judge. It is unlikely that this judge will be the same one who approved the initial period of treatment.

\section{Partially compliant patients}

The pre-Rivers procedure did not make a distinction between patients who sometimes refuse medication and those who always refuse it, and did not assess compliance on the day the decision was made. According to medication administration records, four of the ten pre-Rivers patients for whom an extension of treatment was approved were more than 90 percent compliant with medication at the time of the request.

After Rivers, the judges, the lawyers for the hospital, and the MHLS lawyers informally decided that the new procedure would be used only when patients consistently refused medication. The hospital does not proceed if the patient is compliant on the day of the hearing.

This change increased the number of cases scheduled for a final review but withdrawn before this step occurred. In the pre-Rivers sample, clinicians withdrew one case just before the final review because the patient had become compliant. After Rivers, seven cases reached the court calendar but 
were withdrawn before the hearing because the patients had become totally or partially compliant with medication.

\section{Conclusions}

Converting from a clinical administrative procedure for approving involuntary treatment to a more stringent legal procedure did not delay or diminish requests for or approval of involuntary treatment at Manhattan Psychiatric Center. Patients for whom involuntary treatment was sought were severely ill, frequently dangerous, and sometimes unable to accept help of any kind. It is possible that complexity of the procedure did not play a role in the staff's willingness to pursue involuntary treatment for certain patients, because the determining factor in their decision to seek treatment was the severity of the patients' illness rather than the complexity of the procedure.

The new procedure had several advantages. It helped shift clinicians' focus away from the patient's dangerousness and onto the patient's capacity to make treatment decisions. Although the sample of post-Rivers cases is small, our analysis suggests that clinicians were more willing to seek involuntary treatment for patients who were neither severely deteriorated nor dangerous.

For patients, the procedure offered considerably greater representation and participation. $\mathrm{Al}$ though most patients received treatment despite their objections, they had the opportunity to hear a detailed discussion of their physician's reasoning and to present their own views. Some patients may gain a better understanding of the need for treatment through a process that offers this degree of patient involvement.

The new procedure is more costly than the pre-Rivers procedure. More staff time and more participation by personnel in the legal system are required. Other disadvantages include the lack of a simple process for extending the period of involuntary treatment and lack of a formal procedure for handling partially compliant patients. These last two problems may be resolved as the procedure is refined.

The Rivers court had hoped that the new procedure would allow for the establishment of legal standards for the risks, benefits, and intrusiveness of different treatments. This was not possible. Judges do not have the expertise to make treatment decisions and almost always defer to physicians. Although an independent psychiatrist can be called in, this rarely occurred during the period under study. The lack of an independent clinical review is probably the greatest deficiency in the new procedure.

The Rivers case was brought on behalf of patients in the state hospital system, and generalization to other settings may be problematic. For example, an acute care unit in a general hospital without onsite legal services may find the new procedure impossibly time consuming and complex. Considerable frustration is likely to occur in facilities that lack the time and resources to carry out the postRivers procedure.

Finally, the results of this study suggest that it is more important to focus on whether an involuntary treatment procedure gives expression to sound legal and clinical principles than to argue over whether physicians or courts should be making the final decisions.

\section{Acknowledgments}

The authors thank Stanley Hoffman, Ph.D., and Roberta Rosenfeld, M.P.H., for their assistance with data collection.

\section{References}

1. Appelbaum PS, Gutheil TG: The Boston State Hospital case: "involuntary mind control," the Constitution, and the "right to rot." American Journal of Psychiatry 137:720-723, 1980

2. Mills MJ, Yesavage JA, Gutheil TG: Continuing case law development in the right to refuse treatment. American Journal of Psychiatry 140:715719,1983

3. Sadoff $R L$ : Patient rights versus patient needs: who decides? Journal of Clinical Psychiatry 44:27-32, 1983

4. Stone AA: The right to refuse treatment. Archives of General Psychiatry 38:358-362, 1981

5. 14 NYCRR 27.8 , eff Sept 10, 1975

6. Rivers v Katz, 67 NY 2d 485 (NY 1986)

7. Appelbaum PS, Hoge SK: The right to refuse treatment: what the research reveals, in The Right to Refuse Treatment. Edited by Parry J. Washington, DC, American Bar Association, 1986

8. Appelbaum PS, Gutheil TG: Drug refusal: a study of psychiatric inpatients. American Journal of Psychiatry 137:340-346, 1980

9. Marder SR, Mebane A, Chien C, et al: $A$ comparison of patients who refuse and consent to neuroleptic treatment. American Journal of Psychiatry 140:470-472, 1983

10. Marder SR, Swann E, Winslade WJ, et al: $\Lambda$ study of medication refusal by involuntary psychiatric patients. Hospital and Community Psychiatry 35:724-726, 1984

11. Zito JM, Routt WW, Mitchell JE, et al: Clinical characteristics of hospitalized psychotic patients who refuse ancipsychotic drug therapy. American Journal of Psychiatry 142:822-826, 1985

12. Young JT, Bloom JD, Faulkner LR, et al: Treatment refusal among forensic inpatients. Bulletin of the American Academy of Psychiatry and the Law 15:5-13, 1987

13. Zito JM, Lentz SL, Routt WW, et al: The treatment review panel: a solution to treatment refusal? Bulletin of the American Academy of Psychiatry and the Law 12:349-358, 1984

14. Arkin HR: Forcible administration of antipsychotic medication. JAMA 249:2784-2785, 1983

15. 14 NYCRR 527.8, eff Aug 6, 1986

\section{Correction}

In the News \& Notes section of the July issue, the last line was dropped from the article about the congressional report criticizing the funding cutbacks at the National Institute of Mental Health. The last sentence (on page 796) should have said that the report called for giving NIMH internal authority to make staffing decisions. 